\title{
Manifestation of Pragmatic Failure in Intercultural Communication
}

\author{
Yongchang Ren ${ }^{1, a}$, Yanming $\mathrm{Li}^{2, \mathrm{~b}}$, Qiao Wang ${ }^{1, \mathrm{c}}$ \\ ${ }^{1}$ College of Information Science and Technology, Bohai University, Jinzhou, 121013, China \\ ${ }^{2}$ School of Applied Technology, University of Science and Technology Liaoning, Anshan, 1114000, \\ China
}

a1213552916@qq.com, basliyanming@163.com, '904268105@qq.com

Keywords: intercultural communication; pragmatic failure; manifestation; language pragmatic failure, social pragmatic failure, pragmatic behavior failure

\begin{abstract}
Pragmatic Failure in Intercultural Communication is a hot issue in recent years, with language learning and intercultural communication studies, Pragmatic manifestation of failure is an important part of your mistakes in the field of research. Firstly, to build cross-cultural Pragmatic Communication Failure manifestations structure, then we studied the language pragmatic failure, social pragmatic failure and pragmatic behavior failure. Wherein, language pragmatic failure, pragmatic person research capacity due to the lack of proper understanding, or lack of use of language features to express the intention of generating errors; Social pragmatic failure, of different cultural backgrounds language communicators language habits and characteristics, so decent use of language and avoid mistakes; Pragmatic behavior failure, research is needed to transmit information through the use of methods or means do not belong to the category of speech, expression expressive approach.
\end{abstract}

\section{Introduction}

Intercultural Communication refers to native speakers and non-communication between native speakers, or communication between people of different cultural backgrounds. Accelerate the flow of the process of modernization spiritual and material goods, the various ethnic groups into a common "global village", the intercultural communication has become indispensable in the life of every nation part. Due to the different ecological, physical, social and religious of different nationalities in which environmental, each locale had different language habits, social culture, customs and other contextual factors. Causing people to speak different cultural backgrounds different ways or habits. Cultural differences are cross-cultural communication barriers, overcome communication barriers caused by cultural differences has become a problem facing the entire world. Whether the communication between people is successful, in addition to the two sides of the intermediary language application ability, to a large extent, is also subject to the foreign culture of sensitivity and tolerance, that is to understand each others thinking habits, cognitive model, cooperative attitude, etc., but also to the cultural background, customs and habits of communication. Pragmatic Failure in Intercultural Communication is a hot issue in recent years, with language learning and intercultural communication studies. Pragmatic failures in performance in many ways.

Specifically, the speaker does not see the object, the two sides of the occasion, status, identity and communication disregard or violate the social norms of the Statute or communication unknowingly, unique cultural values contrary to the object language substandard time and space, so as to cause interruption or failure of communication behavior, to make the language of communication encountered obstacles, leading to communication can not achieve the desired effect or reach satisfactory communicative effect. To achieve effective communication and proper understanding, communication not only to master the formal rules of language, but also know how to use the rules of language, that pragmatic rules and social pragmatics statute. Depth study of the language with the manifestations of mistakes, help to enhance intercultural Pragmatic Differences in sensitivity and importance, and to improve intercultural communication skills. 


\section{Manifestation Structure}

From a pragmatic point of view, pragmatic failure is due to lack of accurate understanding of human conversation or effective use of language ability, representation or understanding caused by mistakes. From the perspective of information theory, pragmatic failure is communication with different cultural backgrounds both sides, because we can not fully shared two completely different semantic systems produced, although the language used in the same communication, the exchange of information but does not expect to each other manner, so that the transmission of information shifted. British linguist Jenny Thomas intercultural pragmatic failure into language Pragmatic Failure and Social Pragmatic Failure in two kinds. Combined with results of previous studies, this article will Intercultural Pragmatic summed up with manifestation mistakes as "language pragmatic failure, social failure Failure with a behavior and language" categories, structure shown in Fig. 1.

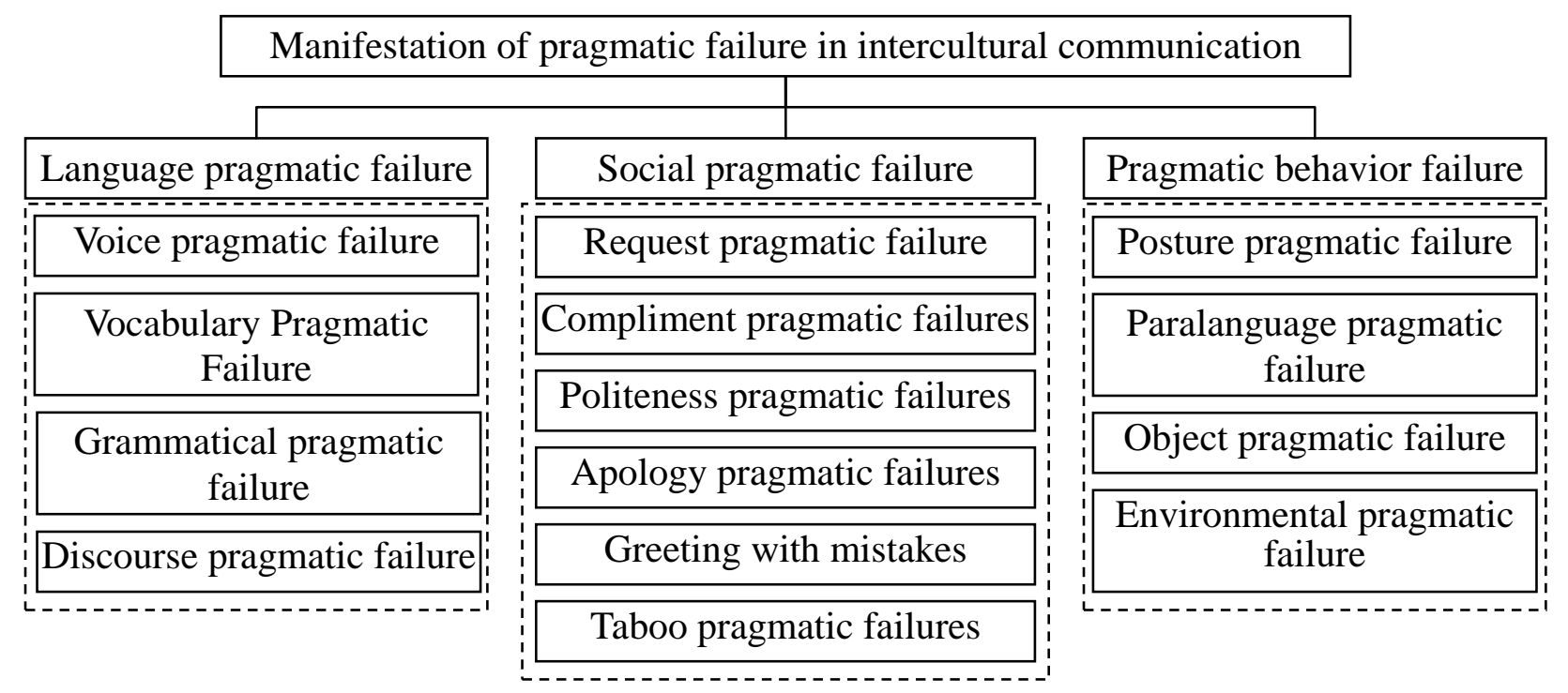

Fig. 1. Manifestation structure of pragmatic failure in intercultural communication

\section{Language pragmatic failure}

Linguistic pragmatic failure refers to the pragmatic meaning of a word or structure of a word or structure in the language of the language, and the error caused by the use of a foreign language, that is, the discourse of the force which is not intended to convey. The national staff of non-use of the target language expressions do not meet the nation's language habits, non-ethnic staff by semantic and structural native inappropriate to apply to the national language in the past. Pragmatic Failure speaker believes the hearer is able to fully understand their own words, obedient people Pragmatic Failure to make the wrong performance is pragmatic inference. Does not exist between any two languages and other terms of the absolute expression of some languages will vary geographically, social customs, lifestyles, etc. The use of different means of expression. Language pragmatic failure is divided into the following four categories [1-5]:

(1) Voice pragmatic failure. Voice is the material shell language is the carrier of the language symbol system. There are the physical basis of speech pitch, sound intensity, sound length, tone, which is composed of four elements of speech. It is due to two languages in syllable structure, stress and intonation, rhythm and rhyme and other parties and the existence of errors generated big difference. If viewed from distinguishing characteristics, the difference between the two languages, first in their different voice, Intercultural Communication, if the characteristics of the target language speech do not know enough, can not pronounce correctly grasp the principles and methods, can easily cause voice on Pragmatic Failure;

(2) Vocabulary Pragmatic Failure. Any language are developed in a certain social and historical conditions up vocabulary is material to build language, vocabulary and therefore are bound to go through the same development process. Different conditions for the development of 
different languages, vocabulary development also according to their different conditions for the formation of different development trajectories. In cross-cultural communication process exposed to new vocabulary, it is natural to think up in Correspondingly, a word, and then the word equate the use of two languages, which resulted in the failure to use the vocabulary;

(3) Grammatical pragmatic failure. Syntax and pragmatics are closely related, grammatical construction of the language rules, pragmatics is decent use these rules in a variety of contexts. Grammatical competence and can not be equated with the ability, sometimes high level of human grammar, pragmatic competence is not necessarily strong. But no grammatical competence, pragmatic competence would not be achieved. Communicators in principle the concept of grammar is not formed until the target language, in the way the grammatical structure of the target language understanding often engendered ideological confusion, resulting in cross-cultural communication Pragmatic grammar mistakes;

(4) Discourse pragmatic failure. Text is the actual use of language units, one or more segments or sentences language, is the language of the whole communication process or a series of consecutive sentences constituted discourse. Functionally, it is equivalent to a communicative act. Discourse between the components, in the form of a convergence in semantically coherent. Due to the influence of different social, historical and cultural background, thinking there are obvious differences. The performance of different semantic structure and organization in the discourse. Common mistakes discourse is coherent statement of convergence errors and semantic errors.

\section{Social pragmatic failure}

Every culture has unique content and meaning, hidden behind a set of moral values, value systems, social customs, it is a non-standard thinking characteristics, these factors influence the use of language. Social Pragmatic Failure caused not because of a violation of grammatical rules, derived from the way of thinking in different cultures and customs of different, cross-cultural communication, or do not understand the social and cultural background conversation ignore each other, resulting in the process of language use and understand mistakes on. On the other side do not understand the cultural background, often inadvertently will put their own unique culture and consciousness, imposed by the form of the language to each other, without regard to whether these language habits of expression in line with the target language, communication norms. Social Pragmatic Failure actually originated in the cultural conflict with the values of the people concerned. Social Pragmatic Failure is divided into the following six categories [6-11]:

(1) Request pragmatic failure. In the West there is a big difference in terms of the request language. Request language acts as a universal communicative acts owned by each community and group, is characterized by the listener have the freedom to choose whether to accept or reject the request. If you use your own social norms exercise or request for interpretation of speech acts to other languages, it may lead to pragmatic failure. This pragmatic failure causes the speaker just caught literally language, ignoring the implication hearer because of different cultures and not literally caught outside.

(2) Compliment pragmatic failures. Compliments is a polite speech act for the listener advantages and strengths affirmative comment. But in the West there are different cultural norms in the use of courtesy, if not pay attention to these cultural differences, prone to lead to pragmatic failures of communication can not be carried out smoothly. In western culture, the man in the face, body, dress and other aspects of the woman to compliment is a very common thing, but in the Chinese traditional culture, this is a taboo. Although the situation is slightly improved, but due to the specific situation of various factors, some aspects of the female form of flattery is still limited.

(3) Politeness pragmatic failures. Polite common to all cultures and peoples, the canonical people's behavior, but also regulates social relations. However, due to different ways of thinking and ethnic differences between different cultures, Politeness and there is a huge difference in the expression. Chinese traditional culture to promote the pecking order in terms of salutation, care for the young. But pay attention to the equal status of Western culture, usually directly call each other names. Because people like to hear others praise, praise interpersonal language is naturally 
indispensable expression, Westerners are willing to praise themselves and their loved ones, but the Chinese people to raise themselves to belittle others advocate.

(4) Apology pragmatic failures. Apology is a process of communication remedies that can effectively restore the communication process between the two sides. How to apologize and apologize reception, Communication and Intercultural Communication is a very important part of the process. Speech act of apology is to speak openly admit doing things should not be done or not done should be done, apologize function is to remedy some rude words and deeds, to establish or restore harmonious relations between the two sides talk, know when to apologize and how apology speech polite society is an important component.

(5) Greeting with mistakes. Greeting people using one of the most frequent form of verbal communication in communication, in any nation of verbal communication plays an important role, but also reflects the various ethnic groups of different culture and communication habits, in cross-cultural communication the first is related to the call and greeting ritual, which smooth cross-cultural communication has an important role. Because different countries and peoples of different cultural backgrounds and historical origins, as well as language greeting used is also very different greeting improper use of communication exchanges between the two sides will create communication barriers.

(6) Taboo pragmatic failures. In the verbal communication process, sometimes people say certain prohibited or taboo words or discourse, which is the language taboo. Its emergence and presence of a significant social and historical roots, and any kind of social and cultural taboos exist language. Due to differences in history, social systems, cultural traditions, customs and values of the West and so on, the content and form of the language is also different taboos. By analyzing Taboos in English and Chinese, can effectively avoid violating taboos language language problems lead to mistakes in Intercultural Communication.

\section{Pragmatic behavior failure}

Pragmatic Communication behavior that is non-verbal behavior, refers to the process to pass through the use of methods or means of speech does not belong to the category of information, express emotion. As a way and means of information transmission, pragmatic behavior in certain social situations in the role will be far better than the role of the language itself. Pragmatic behavior takes many forms, in all its manifestations outside the scope covers the language, such as facial expressions, head movements, posture and attitude, instruments, sound, smell, etc., also includes language communicators in the communication process held distance, time, etc. were silent and the exchange of verbal communication in the process of arising. These silent nonverbal behavior due to cultural differences and show different meanings, resulting in different communicative effects. Pragmatic Failure behavior is divided into the following four categories [12-15]:

(1) Posture pragmatic failure. Body language is non-verbal communication is used widely, variety, and most associated with verbal communication body language. Body language is also a carrier of culture, including the ability to display communication information for all the various parts of the body movements, such as shaking hands, stomping, hugging, smiling, staring, nodding like. In the communication process, if the communication's body movements in certain parts of the other side does not seem appropriate or inappropriate, and even deeper misunderstanding arises body Pragmatic mistakes.

(2) Paralanguage pragmatic failure. Deputy language there is a narrow sound phenomenon, generalized sub language means silent and tangible phenomenon, referred to herein as the narrow sub language. Pragmatic Failure include silence, discourse improper conversion, or for some non-semantic sounds improper use. Silent non-verbal ways to deliver information, conversation is not clear to make a voice of representation. Oriental culture believes silence is positive, has rich connotations. Western culture believes silence is negative, it is the lack of confidence in the performance.

(3) Object pragmatic failure. Object language is an important tool to convey the speaker's cultural identity and personality characteristics, including appearance, clothing, accessories, color 
and odor. In cross-cultural communication, it may cause different aesthetic object Pragmatic turnovers, which is particularly prominent in terms of color words. For example, the Brazilians avoid green, yellow bogey Japanese, Thai people avoid red, blue Belgian bogey, bogey suit Turks, Europeans avoid black.

(4) Environmental pragmatic failure. Environment, including time information and spatial information. Environment Pragmatic Failure is time information and information space grasp errors caused by improper. Time information including time of calculation and attitudes, different cultures understand the concept of time is different. Spatial information includes the treatment of crowded attitude, the concept of territory, communication distance, seating arrangement between the two sides and the like. Communication in people of different cultures and space-related space requirements are also different.

\section{Conclusion}

Pragmatic Failures in Intercultural Communication is a common phenomenon. Pragmatic Failure to intercultural communication, English teaching has practical significance. On the one hand, to help people from different cultural backgrounds to better understand each other and realize that they deem appropriate discourse, in different cultural atmosphere of speech may not be normal behavior, we found the cause of communication barriers, and to take effective remedial measures, adjust their speech codes of conduct to avoid communication conflicts. On the other hand, to achieve intercultural communication, language form only correctness is not enough, because the language manifested in language and culture failures, cultural differences are still the main reason is pragmatic failure. At any time, cross-cultural communication pragmatic failure, who must rely on communication to solve communication capabilities continue to improve, by improving communication's intercultural communicative competence, expanding consensus, narrowing the gap between the two sides in order to gradually construct appropriate consultation and intercultural communication The new statute, to adapt to the new environment, adjust the words and deeds of specification, the two sides reached communicate better.

\section{Acknowledgement}

This work is supported by social science fund project of Liaoning province (L14BYY014): Research on Pragmatic Failure and Its Strategy for Intercultural Communication.

\section{References}

[1] H. F. Tang, "A Discussion on the Pragmatic Failures of Phonetic Problems in Cross - Cultural Communication," Journal of Huanggang Normal University, vol. 28, no. 2, pp. 102-105, 2008.

[2] F. He, "On pragmatic failure of vocabulary in cross cultural communication," Master's degree of Heilongjiang University, 2012.

[3] J. Zhao, "Study of pragmatic failure in Chinese grammar learning of foreign students," Journal of Educational Institute of Jilin Province, vol. 29, no. 7, pp. 60-62, 2013.

[4] W. Zhao, "The New Development of Discourse Pragmatics: A Review of Studies in English and Chinese Discourse Pragmatics," Shandong Foreign Language Teaching Journal, vol. 22, no. 3, pp. 102-105, 2011.

[5] L. H. Liao, "An analysis of discourse errors in college students' English writing and Countermeasures," Journal of Language and Literature Studies, vol. 29, no. 9, pp. 114-116, 2009.

[6] M. X. Zhu, "A study of Socio - Pragmatic Failures by Foreign Students in Intercultural Communication," Master's degree of Southwestern University, 2011. 
[7] H. Liang, "Speech Act Theoretical Analysis of Cross Cultural Pragmatic Failure," Journal of Jilin Institute of Chemical Technology, vol. 32, no. 2, pp. 5-7, 2015.

[8] L. Jiang, "Theoretical analysis of pragmatic failure in cross cultural communication," Journal of Liaoning Economic Vocational Technological Institute, vol. 15, no. 5, pp. 50-51, 2013.

[9] Y. Zhang, J. W. Zhang, "Pragmatic failure of politeness in cross cultural communication," Journal of Educational Institute of Jilin Province, vol. 30, no. 7, pp. 127-128, 2014.

[10] L. L. Zhang, "Analysis about Pragmatic Failure of Chinese Greetings in Cross Cultural Communication," Master's degree of Henan University, 2014.

[11] Z. P. Huang, H. Peng, H. T. He, "The ban of taboo and pragmatic failures," Educational information, vol. 57, no. 14, pp. 26-27, 2014.

[12] Y. Yan, "Forms and Counter - measures of Pragmatic Failure Experienced by Second Language Learners in Intercultural Communication," Journal of Lianyungang Teachers College, vol. 26, no. 4, pp. 27-29, 2009.

[13] S. J. Zhang, D. M. Li, "Analysis of pragmatic failure of body language based on Hofstede Geert," Hei Longjiang Education (Theory \& Practice), vol. 2, no. 10, pp. 43-44, 2014.

[14] X. Fang, "Analysis of nonverbal pragmatic failure in cross cultural communication," Journal of Hotan Teachers College, vol. 29, no. 2, pp. 141-142, 2010.

[15] W. W. Li, "On Redefinition and Reclassification of Cross Cultural Pragmatic Failure," Journal of Chongqing University of Arts and Sciences (Social Sciences Edition), vol. 27, no. 9, pp. 73-76, 2008. 